\title{
PELF Regimen
}

National Cancer Institute

\section{Source}

National Cancer Institute. PELFRegimen. NCI Thesaurus. Code C64787.

A regimen consisting of cisplatin, epirubicin, leucovorin and fluorouracil used for the treatment of advanced-stage gastric cancer. This regimen, developed in Europe, also includes the use of glutathione as a chemoprotectant as well as filgrastim to prevent neutropenia. 